\title{
Hydrodynamics and mass transfer in three-phase magnetic fluidized beds
}

\author{
Chia-Min Chen, Lii-Ping Leu* \\ Department of Chemical Engineering, National Taiwan University, Taipei 106-17, Taiwan
}

Received 1 September 1998; received in revised form 1 August 2000; accepted 4 September 2000

\begin{abstract}
The mass transfer coefficient, liquid axial dispersion and gas holdup have been measured for a gas-liquid-solid magnetic fluidized bed (MFB) as a function of superficial gas velocity, superficial liquid velocity and magnetic field intensity. This study analyzed the volumetric gas-to-liquid mass transfer coefficient $k_{\mathrm{La}}$ to quantify mass transfer in three-phase MFBs.

The solid phase consisted of nickel powder with mean particle diameter of $194 \mu \mathrm{m}$, and the liquid and gas phases were water and air, respectively. An axial magnetic field was supplied by an external solenoid with direct current, the magnetic field being approximately uniform with a maximum relative variation of $2 \%$ across the bed. The volumetric gas-to-liquid mass transfer coefficient $k_{\mathrm{La}}$ was determined from measurements of the steady-state oxygen profile across the bed.

Experimental results showed that the mass transfer rate and average gas holdup in the MFB were higher compared to those of conventional fluidized beds. A $70 \%$ increase in mass transfer coefficient was observed at high magnetic field intensities. Average gas holdup increased by as much as $25 \%$ with increasing magnetic field intensity. The efficiency of mass transfer rate is nearly the same as a solid-free bubble column. The experimental results were compared to the published results of conventional fluidized beds. (C) 2001 Elsevier Science B.V. All rights reserved.
\end{abstract}

Keywords: Fluidized bed; Magnetic field; Mass transfer; Axial dispersion; Gas holdup; Hydrodynamics

\section{Introduction}

Since the pioneering report by Filippov [1], there have been a large number of publications on magnetic fluidized beds (MFBs). Early interest in MFBs was mainly centered around gas-solid reactors, the first systematic work, which was carried out by Rosensweig [2]. To date, the performance of gas-liquid-solid MFBs has not been well-characterized.

$\mathrm{Hu}$ and $\mathrm{Wu}$ [3] examined liquid-solid and gas-liquidsolid MFBs containing $3.6 \mathrm{~mm}$ cubic shaped magnetizable particles and determined the effect of magnetic field intensity on overall and radial variation of gas holdup. They found that overall gas holdup increases with increasing magnetic field intensity. The radial profiles of both gas and solid holdup can be expressed by a parabolic equation under zero or weak magnetic fields. When the fields are

\footnotetext{
* Corresponding author. Tel.: +886-2-2363-5230; fax: +886-2-23623040 .
}

quite strong, the phase holdup distributions become more uniform, and solid holdup is similar to that of a packed bed.

Ouyang et al. [4] and Kwauk et al. [5] examined bubble properties in a three-phase MFB under varying liquid velocity, gas velocity, particle size and surface tension. They found that both bubble size and bubble rise velocity decrease with increasing magnetic field intensity.

Thompson and Worden [6] presented experimental measurements of gas holdup, liquid axial dispersion and gasto-liquid mass transfer coefficients in a three-phase MFB. They found that the average gas holdup decreases by as much as $20 \%$ with increasing magnetic field intensity, and a $30 \%$ increase in gas-to-liquid mass transfer coefficient was observed in the chain-channel regime. Peclet number was relatively unaffected by magnetic field intensity for most bed regimes except for a $400 \%$ increase in the channel regime.

Hristov and Hadzisavvas [7] presented a hydrodynamic study of three-phase fluidized beds in the presence of an external transverse magnetic field, and drew a classification structure of these systems. 
Small particles $\left(d_{\mathrm{p}}<1 \mathrm{~mm}\right)$ have been widely used in biotechnology processes such as aerobic and anaerobic wastewater treatment, cultivation of immobilized and pellet-forming microorganisms. In as much as bubble-coalescing behavior with fine particles under the effect of magnetic field has never been discussed, this paper presents experimental measurements of gas holdup, gas-to-liquid mass transfer coefficients and axial dispersions in a gasliquid-solid MFB containing high density nickel powders.

\section{Experimental}

Fig. 1 shows a schematic diagram of the experimental apparatus. Water flows through a $0.05-\mathrm{m}$ i.d. $\times 0.5-\mathrm{m}$ long Plexiglas column loaded with $0.5 \mathrm{~kg}$ spherical-shaped nickel powders with an average diameter of $194 \mu \mathrm{m}$ (ranging from 177 to $210 \mu \mathrm{m}$ ). The density of the nickel powders is $8900 \mathrm{~kg} / \mathrm{m}^{3}$. Sampling ports are placed at $0.05,0.1,0.2,0.3,0.4,0.45,0.5 \mathrm{~m}$ above the distributor. A perforated plate is used as a distributor for the bed with a fractional free area of $2.0 \%$, designed to prevent channeling. The solid above the supporting grid is placed in an axially uniform magnetic field. The operating mode is magnetization LAST according to the classification of Hristov and Hadzisavvas [7]. The initial bed height is 0.07 $\mathrm{m}$ and the maximum bed height after expansion is about $0.22 \mathrm{~m}$.
A Helmholtz electromagnet comprising two coils having an inner diameter of $0.16 \mathrm{~m}$ and separated by a gap of $0.08 \mathrm{~m}$, produces a uniform and time-invariant magnetic field with an intensity up to a maximum value of 23880 $\mathrm{A} / \mathrm{m}$. Power for the solenoid is provided by a DC power supply (Takasago, EX-375L) rated at $4.8 \mathrm{~A}$ and $27 \mathrm{~V}$. Oil-free compressor air is injected through a stainless-steel ring sparger near the bed bottom. A holding tank containing water is continually sparged with nitrogen gas until the dissolved oxygen concentration is negligible to the airsaturation value. Water withdrawn from the sampling port is immediately transported into a well-mixed cup and its dissolved oxygen concentration is measured.

The valve technique [8] is used to measure the average gas holdup over the entire bed. This is accomplished by simultaneously shutting off the gas and liquid flows and measuring the volume of gas trapped in the bed. The average gas holdup is calculated by dividing the trapped gas volume by the total bed volume.

The steady-state method [9] is used to calculate the gas-to-liquid mass transfer coefficient $k_{\mathrm{La}}$. A mass balance on oxygen in the liquid phase of the bed is shown as:

$\frac{1}{P e} \frac{\mathrm{d}^{2} C}{\mathrm{~d} Z^{2}}-\frac{\mathrm{d} C}{\mathrm{~d} Z}=S t\left(C-C^{*}\right)$,

where the Peclet number, $P e$, and Stanton number, St, are defined as

$P e=\frac{U_{1} L}{D_{\mathrm{a}} \varepsilon_{1}}$

$S t=\frac{k_{\mathrm{La}} L}{U_{1}}$,
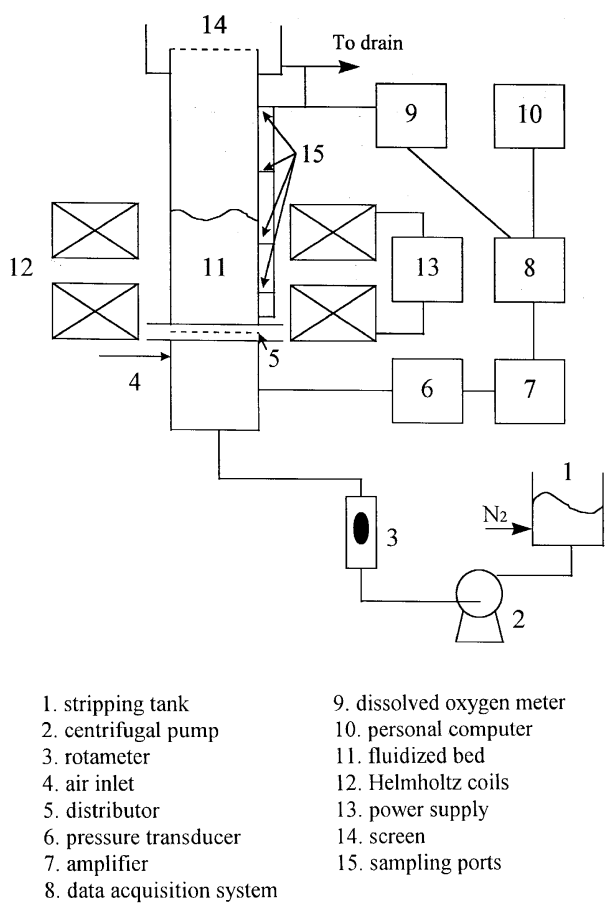

Fig. 1. Experimental setup. the equilibrium oxygen concentration, $C^{*}$, is the function of the depth of bed, thus,

$C^{*}=a+b Z$.

And the following boundary conditions are required:

$$
\begin{aligned}
& Z=0, \quad C=C_{0}+\frac{1}{P e} \frac{\mathrm{d} C}{\mathrm{~d} Z}, \\
& Z=1, \quad \frac{\mathrm{d} C}{\mathrm{~d} Z}=0 .
\end{aligned}
$$

The analytical solution to the above differential equation and boundary condition is:

$C=C^{*}+A_{1} \cdot e^{r_{1} Z}+A_{2} \cdot e^{r_{2} Z}-\frac{b}{S t}$, 
where

$A_{1}=\frac{B \cdot r_{2} \exp \left(r_{2}\right)-b \cdot r_{1}}{r_{1}^{2} \exp \left(r_{1}\right)-r_{2}^{2} \exp \left(r_{2}\right)}$,

$A_{2}=\frac{-B \cdot r_{1} \exp \left(r_{1}\right)+b \cdot r_{2}}{r_{1}^{2} \exp \left(r_{1}\right)-r_{2}^{2} \exp \left(r_{2}\right)}$,

$r_{1}=\frac{P e+\sqrt{P e^{2}+4 S t \cdot P e}}{2}$,

$r_{2}=\frac{P e-\sqrt{P e^{2}+4 S t \cdot P e}}{2}$

$B=P e\left(a-C_{0}-\frac{b}{S t}\right)-b$.

The gas-to-liquid mass transfer coefficient and axial dispersion coefficient are obtained by parameter fitting of the above solution to the experimentally determined dissolved oxygen concentration profile. A nonlinear statistical regression program is employed for the parameter fitting, which gives a minimum value of the sum of squares of the error. One typical example of profile fitting is shown in Fig. 2. The dissolved oxygen concentration profile along the column increases under the effect of the magnetic field.

The second method to determine the axial dispersion coefficient is evaluation by using tracer injection method. Sodium chloride solution $(1.0 \mathrm{~N})$ is injected instantaneously at the bottom of the bed, and its outlet concentrations are measured on-line with a conductivity meter, the signal from the electrode being sent to an IBM PC through

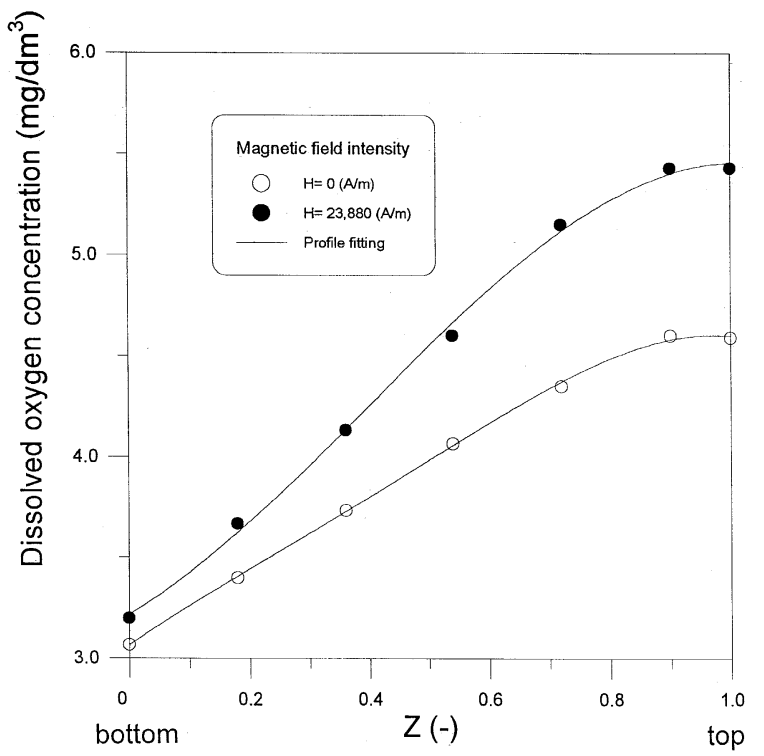

Fig. 2. Comparison between profile fitting to axial dissolved oxygen profile.

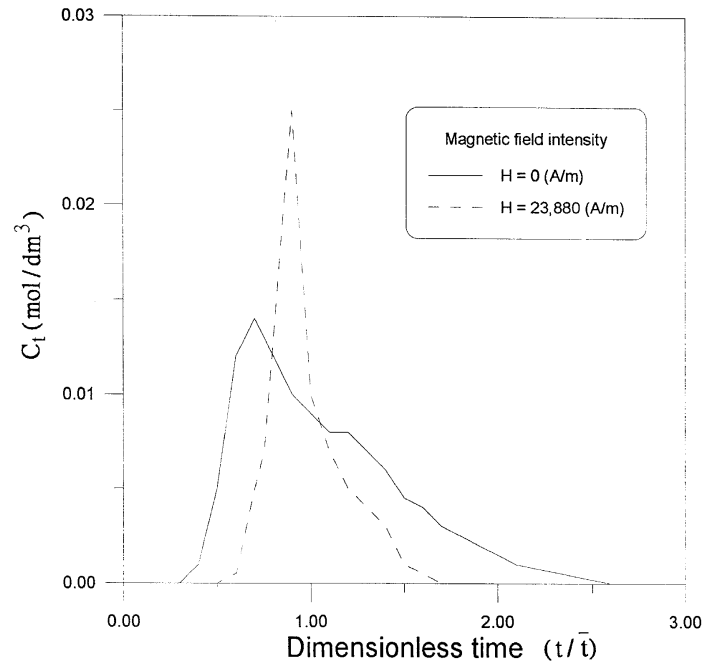

Fig. 3. The tracer response curves in three-phase magnetic fluidized beds.

a RS232 interface. The dimensionless time variance $\sigma^{2}$ of the tracer response curves is computed by use of the following relationships:

$\bar{t}=\frac{\int_{0}^{\infty} t C_{\mathrm{t}} \mathrm{d} t}{\int_{0}^{\infty} C_{\mathrm{t}} \mathrm{d} t}$,

$\sigma^{2}=\frac{\int_{0}^{\infty}(t-\bar{t})^{2} C_{\mathrm{t}} \mathrm{d} t}{\int_{0}^{\infty} C_{\mathrm{t}} \mathrm{d} t}$.

Peclet numbers, computed on-line from the variance of the tracer response curves with closed-open vessel assumption are used to calculated the axial dispersion coefficient [10] from the following equation:

$\sigma^{2}=\frac{1}{P e^{2}}(2 P e+3)$

One typical response curve of tracer is shown in Fig. 3. The response curve of tracer in the MFB is significantly sharper than that without an applied magnetic field. It means that the flow pattern of liquids tend to be plug flow under the effect of the magnetic field.

\section{Results and discussion}

\subsection{Flow regime and gas holdup}

The regime map based on bubble flow [11] is shown in Fig. 4. The boundary between dispersed bubble and coalesced bubble is independent of gas velocity. With the 


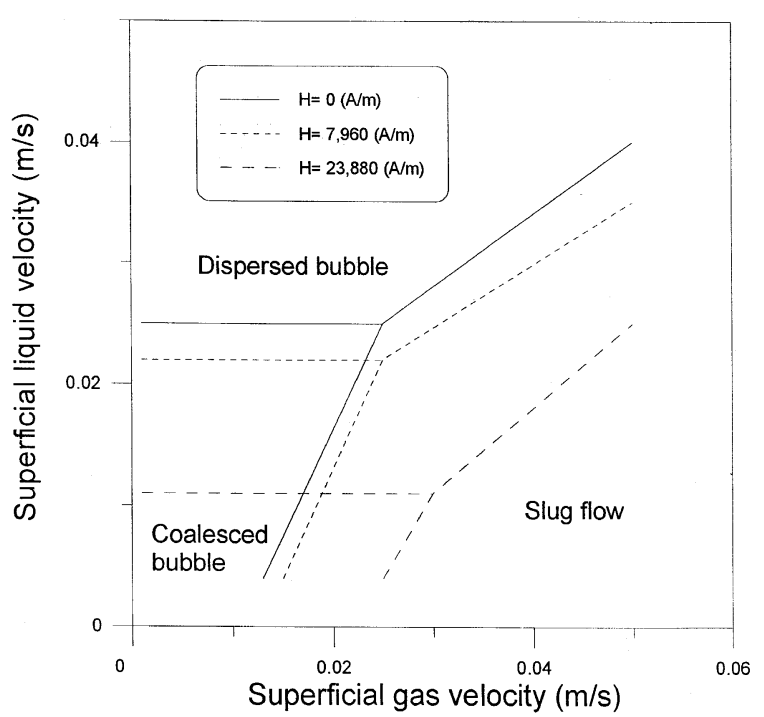

Fig. 4. The flow regime map of three-phase magnetic fluidized beds.

introduction of a magnetic field, the dispersed bubble regime was expanded due to bed contraction and enhanced bubble splitting.

Fig. 5 shows that the average gas holdup increased with increasing gas velocity and magnetic field intensity. Results given are the average of at least five replicates with an average standard deviation of $7 \%$. The increase in average gas holdup is consistent with the common observation that bubbles break up with increasing magnetic field intensity. A similar result was reported by $\mathrm{Hu}$ and $\mathrm{Wu}$ [3]. In this study, the application of magnetic field resulted in smaller bubbles which rose more slowly than the larger ones, thus increasing the gas holdup.

In Fig. 6, the average gas holdup data without applied magnetic fields are compared to correlations published by Begovich and Watson [12]. Despite the differences in

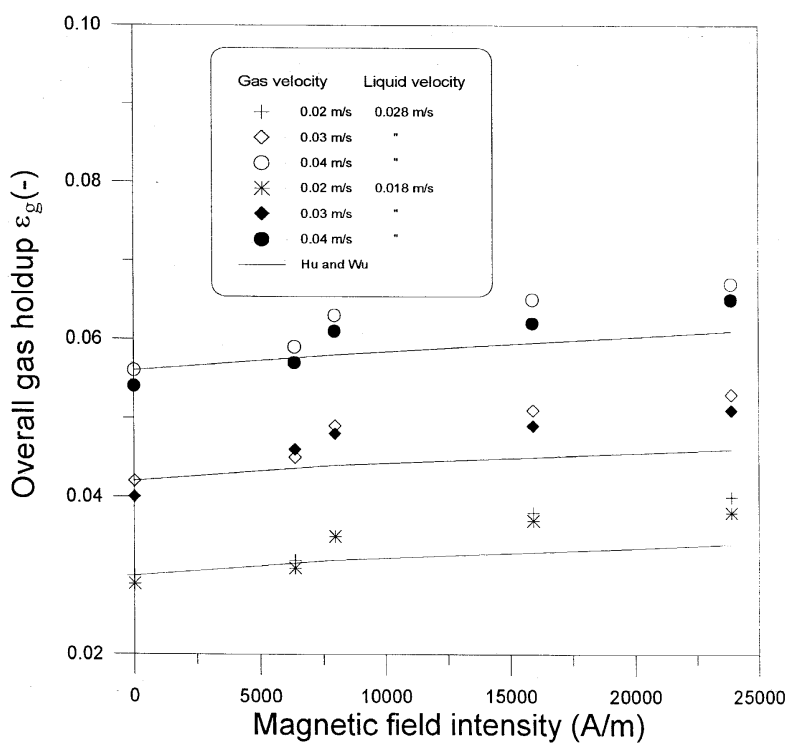

Fig. 5. Effect of magnetic field intensity on overall gas holdup.

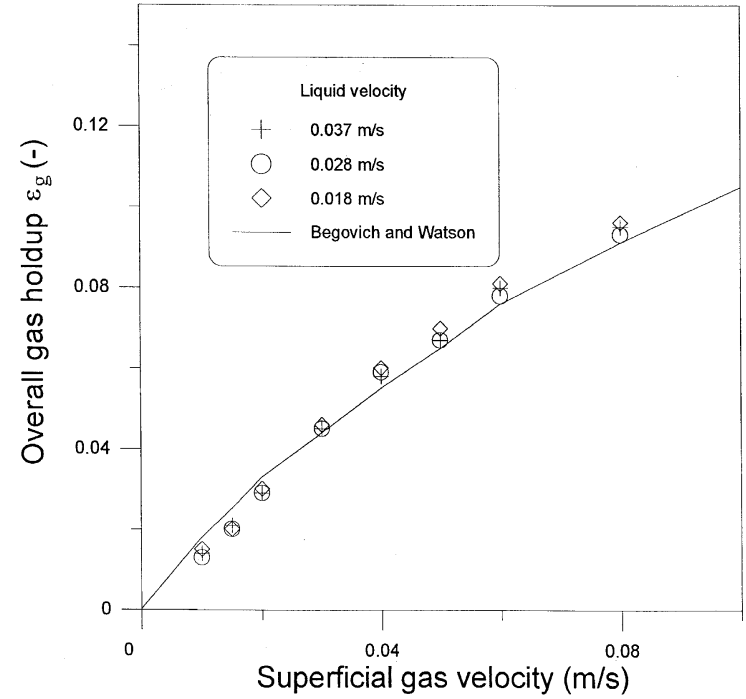

Fig. 6. Comparison of gas holdup data as a function of liquid and gas velocity without magnetic field.

particle density, our data are in good agreement with the correlations. The effect of liquid velocity on average gas holdup is not significant. This trend is consistent with the finding of $\mathrm{Hu}$ and $\mathrm{Wu}$ [3], who reported that the effect of liquid velocity on average gas holdup can be neglected.

Based on the 45 experimental data obtained in this work, the following empirical correlation was obtained (SI unit):

$\varepsilon_{\mathrm{g}}=0.75 U_{\mathrm{g}}^{0.78} \exp \left(8.12 \times 10^{-6} H\right)$.

The average relative error is $8.5 \%$ in this correlation. The effect of magnetic field intensity on gas holdup was more pronounced for the smaller particles used in this study $(194 \mu \mathrm{m})$ as compared to the larger particles (3.6 $\mathrm{mm}$ ) used by $\mathrm{Hu}$ and $\mathrm{Wu}[3]$.

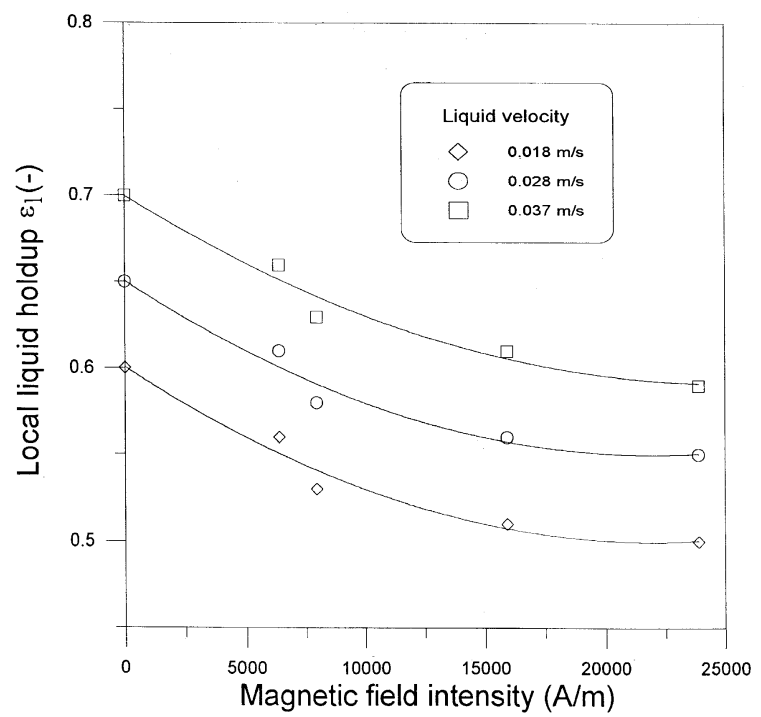

Fig. 7. Effect of magnetic field intensity on local liquid holdup (gas velocity $=0.02 \mathrm{~m} / \mathrm{s}$ ). 


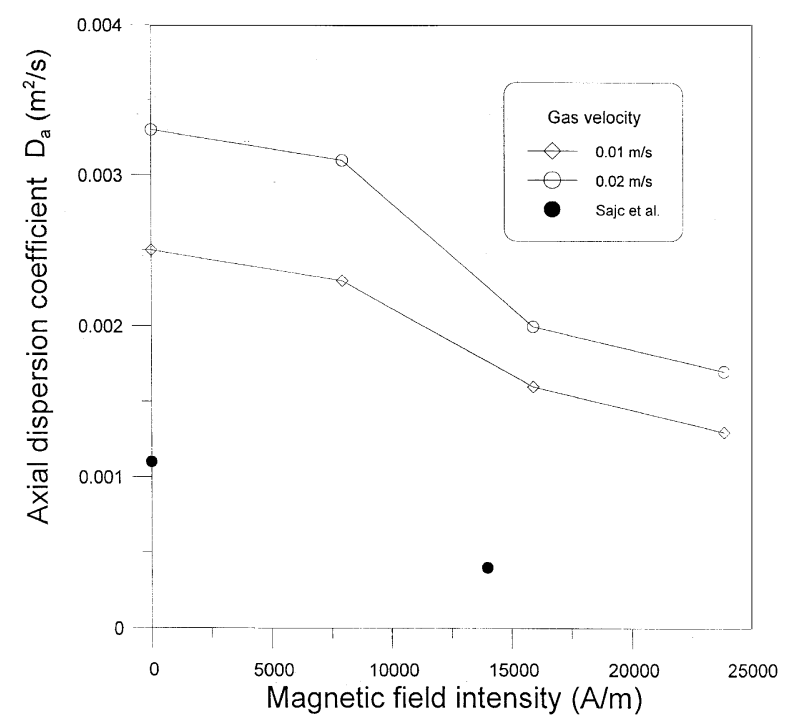

Fig. 8. The axial dispersion coefficient obtained from tracer experiment as a function of magnetic field intensity and gas velocity (liquid velocity $=0.037 \mathrm{~m} / \mathrm{s}$ ).

Fig. 7 shows that the local liquid holdup at different liquid velocities decreased with magnetic field intensity due to bed contraction. This trend is consistent with the finding of Thompson and Worden [6]. Correlation of the 45 data points is as follows, with an $11.5 \%$ relative error (SI unit):

$\varepsilon_{l}=1.49 U_{1}^{0.228} \exp \left(-8.3 \times 10^{-6} H\right)$

\subsection{Liquid axial dispersion}

\subsubsection{Tracer injection method}

The tracer injection method used to determine the axial dispersion coefficients has been given elsewhere (Chen

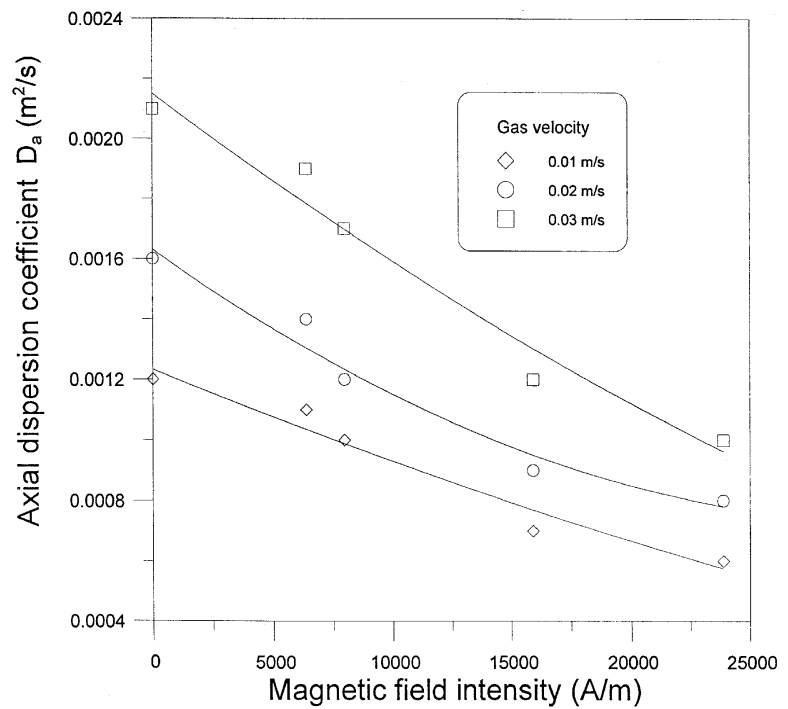

Fig. 9. Effect of magnetic field intensity and gas velocity on axial dispersion coefficient obtained from profile fitting (liquid velocity $=0.037$ $\mathrm{m} / \mathrm{s})$. and Leu [13]). One typical tracer response curve is shown in Fig. 3. Fig. 8 shows that the axial dispersion coefficient remained almost unchanged at low magnetic field intensity, but decreased significantly at high magnetic field intensity. Such behavior can be explained from the observation of bubble break up, but little coalescence at low magnetic field intensity, and intense bubble splitting at high magnetic field intensity.

The present experiments showed that the flow pattern of liquid under low magnetic field intensity is similar to that of a conventional fluidized bed, but approaches that of a packed bed under high magnetic field intensity.

Dispersion data taken from Sajc et al. [14] show a similar trend compared to this work. Furthermore, in this work, the decrease of axial dispersion coefficient with increasing magnetic field is consistent with the increasing gas holdup and the decreasing bubble diameter.

(a) Gas velocity $=0.01 \mathrm{~m} / \mathrm{s}$

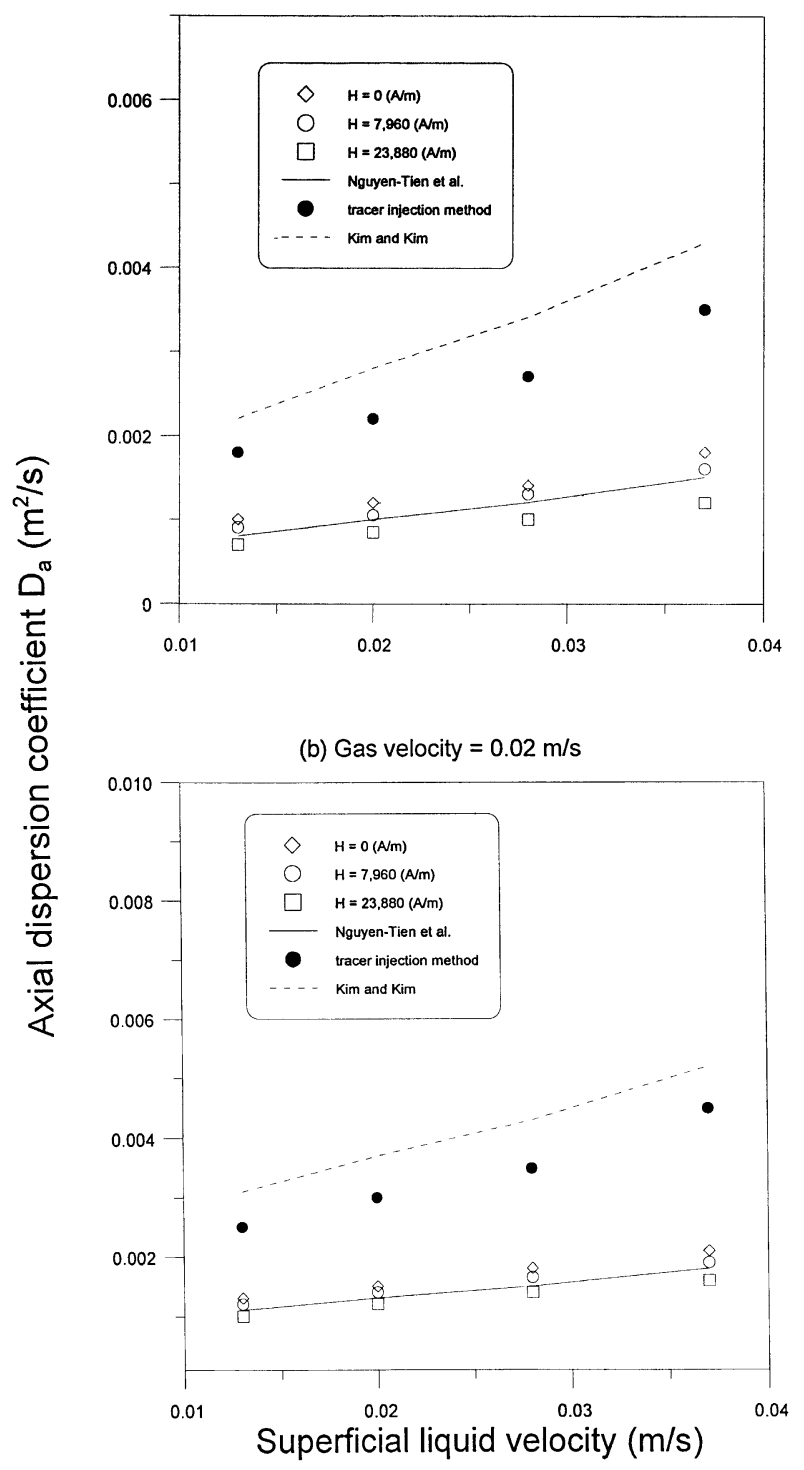

Fig. 10. Comparison of axial dispersion coefficient to literature data. 


\subsubsection{Profile fitting of dissolved oxygen concentration}

Profile fitting of dissolved oxygen concentrations as shown in Fig. 2, while Fig. 9 shows the effect of magnetic field intensity and gas velocity on axial dispersion coefficient $D_{\mathrm{a}}$, indicating similar trends for the tracer injection method.

Bubble wakes contribute to liquid mixing by carrying elements of liquid through the bed. Since bubble size was observed to decrease with increasing magnetic field intensity, the decreasing bubble size is associated with lower backmixing. The considerable difference between the axial dispersion coefficients shown in Figs. 8 and 9 indicates that the tracer injection method may not be appropriate for reactors involving inter-phase mass transfer.

Nguyen-Tien et al. [15] used a well-established method to determine mass transfer coefficient and liquid phase axial dispersion coefficient in three-phase fluidized beds of $0.05-8-\mathrm{mm}$ glass spheres by measuring the steady-state axial oxygen concentration profile along the reactor. Fig. $10 \mathrm{a}$ and $\mathrm{b}$ compare axial dispersion coefficients obtained from this work to those of Nguyen-Tien et al. [15] and Kim and Kim [16]. The correlation of Nguyen-Tien et al. (a) Liquid velocity $=0.013 \mathrm{~m} / \mathrm{s}$

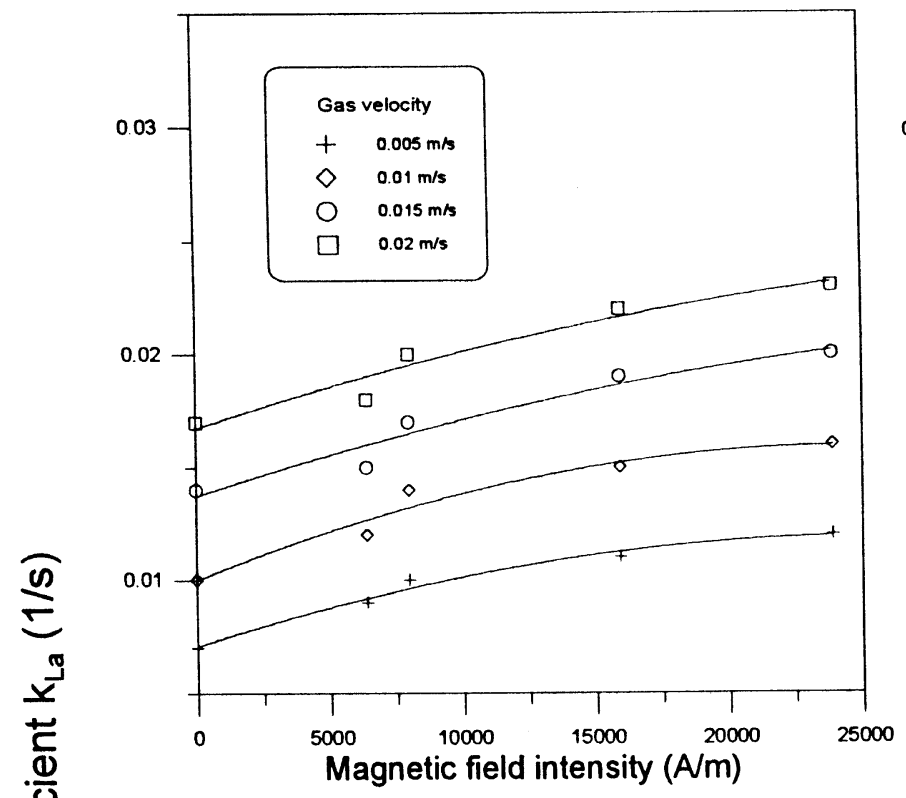

(b) Liquid velocity $=0.028 \mathrm{~m} / \mathrm{s}$

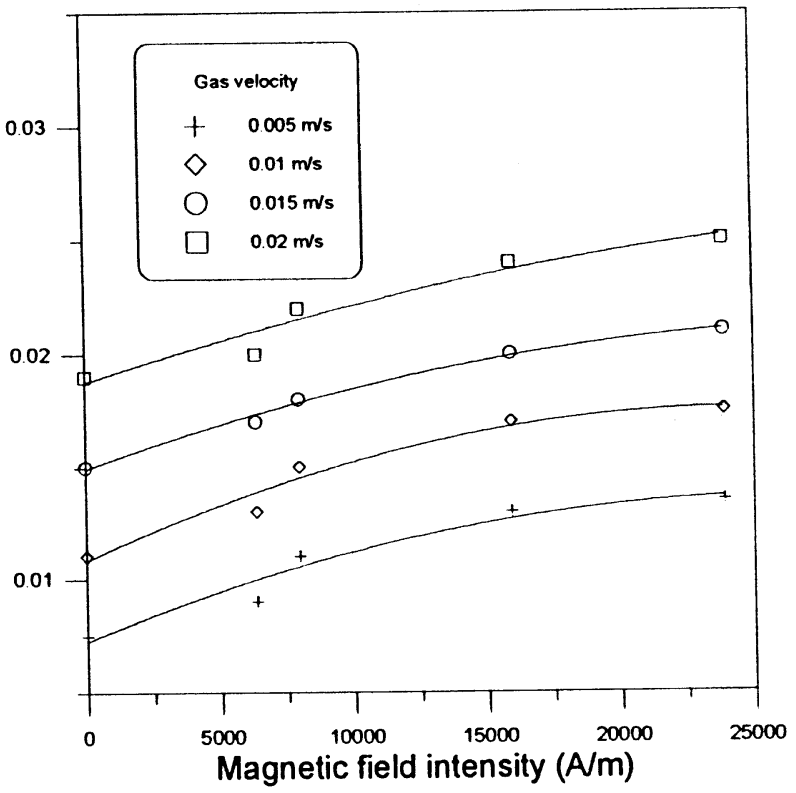

(c) Liquid velocity $=0.037 \mathrm{~m} / \mathrm{s}$

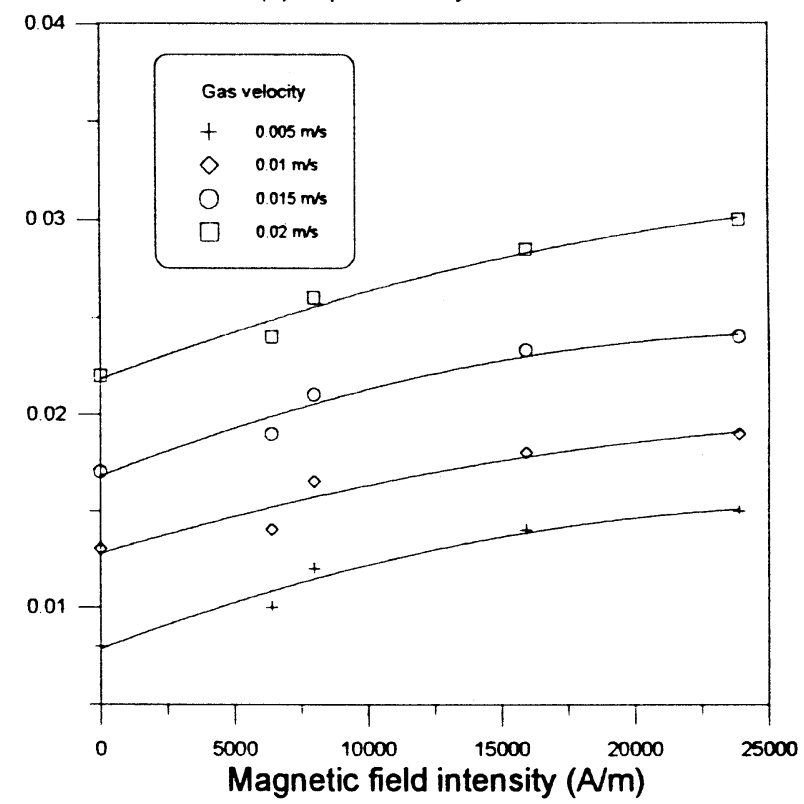

Fig. 11. Mass transfer coefficient as a function of magnetic field intensity and gas velocity. 
[15] gave reasonable agreement with those we measured in this study, while the correlation of Kim and Kim [16] tended to overpredict the axial dispersion coefficients.

Based on the 60 axial dispersion coefficients obtained in this work, the following correlation with a $16.2 \%$ average relative error results (SI unit):

$D_{\mathrm{a}}=3.836 \times 10^{-2}\left(U_{\mathrm{l}}+U_{\mathrm{g}}\right)^{1.03} \exp \left(-2.9 \times 10^{-5} H\right)$.

\subsection{Gas-to-liquid mass transfer}

The very good fit between the model and the experimental concentration profile shown in Fig. 2 demonstrates that the axial dispersion model is appropriate to describe the fluid flow of the present system. Fig. 11a-c show the effect of magnetic field intensity and gas velocity on gas-to-liquid mass transfer coefficient $k_{\mathrm{La}}$ for three different liquid velocities. The mass transfer coefficient increased with increasing gas velocity and more significantly, with magnetic field intensity. Bubble size was observed to be smaller under the effect of the magnetic field, resulting in a higher gas-liquid contact area and gas holdup. The same trend was reported by Thompson and Worden [6], who observed a $30 \%$ increase in mass transfer coefficient in the chain-channel regime.

However, the enhancement effect obtained from this work is nearly proportional to magnetic field intensity for all gas and liquid velocities. The highest increase of mass transfer coefficient of up to $70 \%$ occurred at the lowest gas and liquid velocities. This is due to increased bubble break up under the effect of the magnetic field, leading to decreased bubble size and increased interfacial area. Ouyang et al. [4] and Kwauk et al. [5] reported that the bubble diameter decreases with increasing magnetic field intensity. A similar result was observed in this experiment, particularly that the introduction of magnetic field resulted in bed contraction and smaller bubbles.

The bubble diameter is related to the interfacial area $\alpha$, according to the following geometric identity [6]:

$\alpha=\frac{6 \varepsilon_{\mathrm{g}}}{d_{\mathrm{b}}}$.

In this study, the increase in average gas holdup with increasing magnetic field intensity is shown in Fig. 5. With the decreasing bubble diameter under the effect of the magnetic field, the gas-liquid interfacial area, as well as the mass transfer coefficient, are increased.

Particle size has a major impact on mass transfer coefficient in three-phase fluidized beds, the enhanced bubble growth which occurs in beds of fine particles and the increased bubble splitting, which takes place in beds of coarse particles [17]. The efficiency of mass transfer rate for three-phase fluidization is defined as follows:

$e=\frac{k_{\mathrm{La}}}{k_{\mathrm{La}, \mathrm{bc}}}$,

where subscript bc stands for solid-free bubble column. For bubble-coalescing systems with fine particles, $e<1$; for bubble-splitting systems with coarse particles, $e>1$. The effect of magnetic field intensity on efficiency is shown in Fig. 12a and b, the efficiencies are raised from about 0.60 without magnetic field to about 0.90 with high magnetic field intensity. The dependency of efficiency on gas and liquid velocities is not significant and can be neglected.

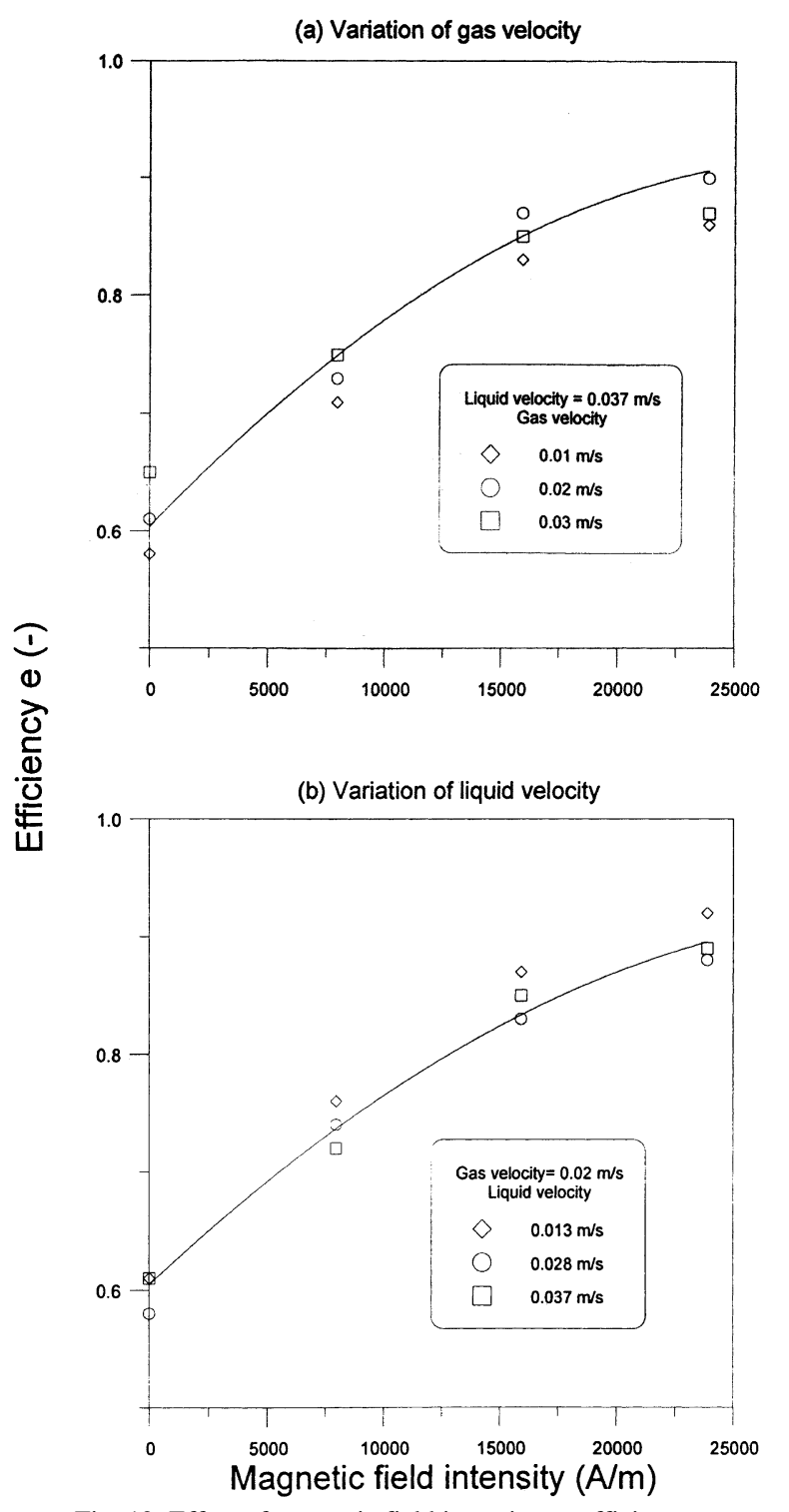

Fig. 12. Effect of magnetic field intensity on efficiency. 


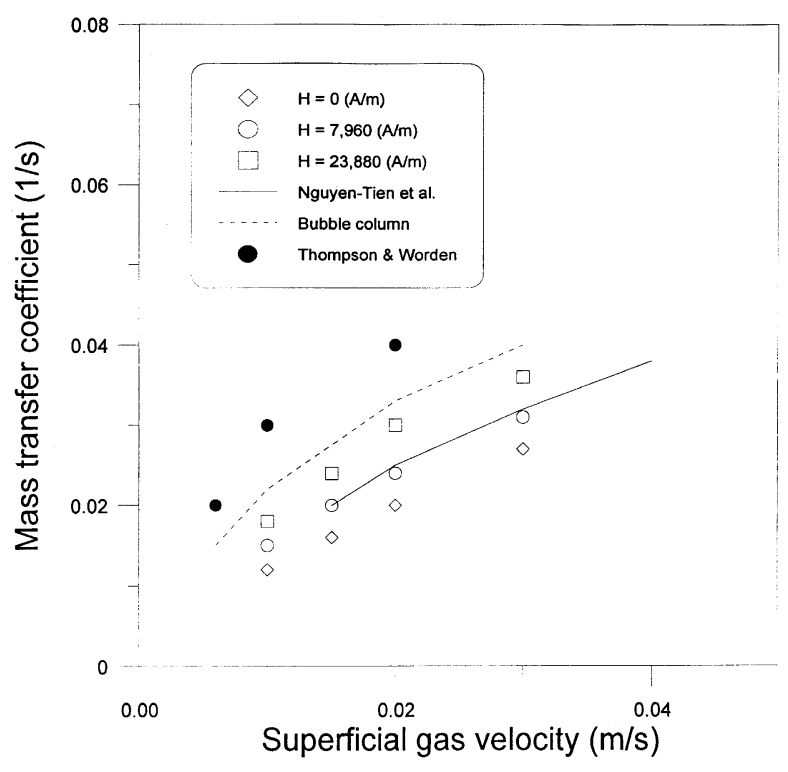

Fig. 13. Comparison of mass transfer coefficient to literature data as a function of gas velocity (liquid velocity $=0.037 \mathrm{~m} / \mathrm{s}$ ).

Nguyen-Tien et al. [18] reported mass transfer data for particle diameters ranging from 0.05 to $1 \mathrm{~mm}$, which can be correlated empirically as follows:

$k_{\mathrm{La}}=0.39\left(1-\frac{\phi_{\mathrm{s}}}{0.58}\right) U_{\mathrm{g}}^{0.67}$.

Fig. 13 compares the mass transfer coefficient obtained from this work to the above correlation (Eq. (21)). The correlation gave values $20 \%$ higher than those measured in this work without magnetic field, possibly due to the solid-density difference. Mass transfer coefficient taken from Thompson and Worden [6] shows significantly higher values than all the other data due to increased bubble splitting in beds of coarse particles. A notable phenomenon is that the mass transfer rate at high magnetic field is nearly the same as a solid-free bubble column, indicating that the mass transfer resistance is reduced under the effect of the magnetic field.

Based on the 60 experimental data obtained in this work, the following overall correlation was obtained (SI unit):

$k_{\mathrm{La}}=0.40 U_{\mathrm{g}}^{0.625} U_{1}^{0.26} \exp \left(1.477 \times 10^{-5} H\right)$.

The average relative error of Eq. (22) is $10.8 \%$.

\section{Conclusions}

The hydrodynamic behavior and mass transfer properties were studied in gas-liquid-solid MFBs. The average gas holdup increased by $25 \%$ with increasing magnetic field intensity due to decrease in bubble size. The mass transfer coefficient increased with increasing magnetic field intensity due to increase in gas-liquid interfacial area (increased gas holdup). A 70\% increase of mass transfer coefficient was observed in a high magnetic field intensity due to the change of flow regime, while the efficiency of mass transfer rate is nearly the same as a solid-free bubble column. The axial dispersion coefficient decreased with increasing magnetic field intensity, suggesting that the flow pattern of liquid tended to be plug flow in three-phase MFBs. High performance contactor could be achieved in three-phase MFBs.

\section{List of Symbols}

$A_{1} \quad$ parameter defined in Eq. (8)

$\mathrm{A}_{2} \quad$ parameter defined in Eq. (9)

$a \quad$ parameter in Eq. (4)

$B \quad$ parameter defined in Eq. (12)

$b \quad$ parameter in Eq. (4) $(1 / \mathrm{m})$

$C$ concentration of oxygen $\left(\mathrm{mg} / \mathrm{dm}^{3}\right)$

$C_{0} \quad$ inlet concentration of oxygen $\left(\mathrm{mg} / \mathrm{dm}^{3}\right)$

$C^{*} \quad$ equilibrium concentration of oxygen $\left(\mathrm{mg} / \mathrm{dm}^{3}\right)$

$C_{\mathrm{t}} \quad$ concentration of tracer $\left(\mathrm{mol} / \mathrm{dm}^{3}\right)$

$D_{\mathrm{a}} \quad$ axial dispersion coefficient $\left(\mathrm{m}^{2} / \mathrm{s}\right)$

$d_{\mathrm{b}} \quad$ bubble diameter $(\mathrm{m})$

$e \quad$ efficiency of mass transfer rate $(-)$

$H \quad$ applied magnetic field $(\mathrm{A} / \mathrm{m})$

$k_{\mathrm{La}} \quad$ gas to liquid mass transfer coefficient $(1 / \mathrm{s})$

$k_{\mathrm{La}, \mathrm{bc}} \quad$ gas to liquid mass transfer coefficient of bubble column $(1 / \mathrm{s})$

$L \quad$ axial distance $(\mathrm{m})$

$\mathrm{Pe} \quad$ axial Peclet number (-)

$r_{1} \quad$ parameter defined in Eq. (10)

$r_{2} \quad$ parameter defined in Eq. (11)

St Stanton number (-)

$t \quad$ time (s)

$\bar{t} \quad$ mean residence time $(\mathrm{s})$

$U_{1} \quad$ superficial liquid velocity $(\mathrm{m} / \mathrm{s})$

$U_{\mathrm{g}} \quad$ superficial gas velocity $(\mathrm{m} / \mathrm{s})$

$Z$ dimensionless axial position. $Z=0$ (bottom), $Z=$ 1 (top) (-)

\section{Greek letters}

$\alpha \quad$ interfacial area/liquid volume $(1 / \mathrm{m})$

$\varepsilon_{\mathrm{g}} \quad$ average gas fraction (-)

$\varepsilon \quad$ liquid fraction (-)

$\phi_{\mathrm{s}} \quad$ solid fraction (-)

$\sigma^{2} \quad$ dimensionless time variance (-)

\section{Acknowledgements}

The authors are grateful to the National Science Council, R.O.C., for financial support. 


\section{References}

[1] M.V. Filippov, Prik. Magnit. Lat. SSR 12 (1960) 215.

[2] R.E. Rosensweig, Science 204 (1979) 57.

[3] T.T. Hu, J.Y. Wu, Chem. Eng. Res. Des. 65 (1987) 238.

[4] F. Ouyang, Y. Wu, C. Guo, M. Kwauk, J. Chem. Ind. Eng. (China, Chin. Ed.) 5 (1990) 206.

[5] M. Kwauk, X. Ma, F. Ouyang, Y. Wu, D. Weng, L. Chang, Chem. Eng. Sci. 47 (1992) 3467.

[6] V.S. Thompson, R.M. Worden, Chem. Eng. Sci. 52 (1997) 279.

[7] J.Y. Hristov, K. Hadzisavvas, Proc. 2nd European Conference on Fluidization, Bilbao, Spain, 1997, p. 573.

[8] S.D. Kim, C.G. Baker, M.A. Bergougnou, Can. J. Chem. Eng. 50 (1972) 695.

[9] W.D. Deckwer, K. Nguyen-Tien, A. Schumpe, Y. Serpemen, Biotechnol. Bioeng. 24 (1982) 461.
[10] E.T. Van der Laan, Chem. Eng. Sci. 7 (1958) 187.

[11] S.D. Kim, C.G. Baker, M.A. Bergougnou, Can. J. Chem. Eng. 50 (1972) 695.

[12] J.M. Begovich, J.S. Watson, in: J.F. Davidson, D.L. Kearins (Eds.), Fluidization, Cambridge Univ. Press, Cambridge, UK, 1978, p. 190.

[13] C.M. Chen, L.P. Leu, in: W.-M. Lu, L.-P. Leu (Eds.), Proc. 5th Asian Conf. Fluidized-Bed and Three-Phase Reactors, Hsitou, Taiwan, 1996, p. 268.

[14] L.M. Sajc, Z.R. Jovanovic, G. Vunjak-Novakovic, G.N. Jovanovic, R.D. Pesic, D.V. Vukovic, Trans. IChemE 72 (1994) 236.

[15] K. Nguyen-Tien, A.N. Patwari, A. Schumpe, W.D. Deckwer, J. Chem. Eng. Jpn. 17 (1984) 652.

[16] S.D. Kim, C.H. Kim, J. Chem. Eng. Jpn. 16 (1983) 172.

[17] N. Epstein, Can. J. Chem. Eng. 59 (1981) 649.

[18] K. Nguyen-Tien, A.N. Patwari, A. Schumpe, W.D. Deckwer, AIChE J. 31 (1985) 194. 